\title{
Small and Medium Enterprises 2.0: Are We There Yet?
}

\author{
Pedro Isaias ${ }^{1}$ and Diogo Antunes ${ }^{2}$ \\ ${ }^{1}$ Universidade Aberta (Portuguese Open University) and ADVANCE - ISEG, \\ Rua Fernão Lopes, 9, $1^{\circ}$ Esq., \\ 100-132 Lisboa - Portugal \\ pisaias@uab.pt \\ ${ }^{2}$ ISEG - Lisboa School of Economics and Management - University of Lisbon \\ Rua do Quelhas, 6, \\ 1200-781 Lisboa - Portugal \\ diogotavaresantunes@gmail.com
}

\begin{abstract}
The concept of Enterprise 2.0 relates to the use of Web 2.0 technologies such as blogs, social networks or wikis, in enterprises and it has been at the centre of several debates among the business community. Controversy aside, many enterprises have already openly adopted and supported the implementation of Web 2.0 technologies. This growing interest in the Social Web as a business resource has captured the attention of Small and Medium Enterprises (SMEs). This paper focuses on the adoption of Enterprise 2.0's practices inside SMEs and uses the Portuguese case as an illustration of the current scenario. It examines the implementation of Web 2.0 tools inside Portuguese elite SMEs and provides guiding principles for the general proficiency of SME 2.0.
\end{abstract}

Keywords: SMEs, Web 2.0, Enterprise 2.0.

\section{Introduction}

The term Enterprise 2.0 (E2.0), coined by McAfee [1], refers to the "use of social software platforms within organizations or between organizations, their business partners and customers".E2.0 stands, thus, for the utilization of Web 2.0 tools within enterprises. There is a plethora of Web 2.0 technologies that can be used for business purposes such as wikis, blogs, Really Simple Syndication (RSS), social bookmarking, podcasts, and social networks. The advantages of incorporating Web 2.0 applications in business are manifested in four core levels: innovation, growth, transformation of customer relationship and cost reduction [2].

SMEs; account for $90 \%$ of all companies in the United States of America and 99\% of enterprises in Europe [3]. Hence, the examining of the proliferation of E2.0 demands the analysis of SMEs and their own practices of Web 2.0 adoption. There is a significant parcel of SMEs that are investing in a proactive attitude toward Web 2.0 technologies' adoption as a manner of addressing their existing knowledge scarcity [4] 
SMEs present a relatively low survival rate. Despite the large number of SMEs that emerge every year, only $40 \%$ of them survive 10 years [5]. These companies operate in an increasingly complex and competitive market which makes their survival challenging [6]. Thus, given the lack of resources and limited innovation capacities of SMEs, E2.0 may be a way to overcome the current difficulties, as it promotes knowledge sharing, internal and external communication [7], collaboration, and productivity, as well as a greater proximity to the market [5]. Web 2.0 technologies are not only free or cheap, but also simple and comfortable to use, which enables their adoption [7].

This paper begins by briefly examining the concept of E2.0 and its extension to SMEs. In order to ignite the outline of a global depiction of the adoption of Enterprise 2.0 inside SMEs peculiar settings, this study presents an empirical research concentrating on the particular case of Portuguese elite SMEs. To conclude, this paper imports the results of this research and outlines a set of guidelines aimed at the successful development of SME 2.0.

\section{Enterprise 2.0}

According to Frappaolo and Keldsen [8] there are three essential elements in the definition of E2.0: collectivity, in the sense that the harnessing of Web- based technology warrants the existence of a system to succeed; Swiftness and agility, that account for E 2.0's flexible nature and user-friendliness; and the notion of extended enterprise, which encompasses enterprises themselves, and their relation with other companies, their costumers or partners. Hence the definition that they provide states that E2.0 is " a system of Web-based technologies that provide rapid and agile collaboration, information sharing, emergence, and integration capabilities in the extended enterprise." [8].. The development of a business strategy that includes Web 2.0, demands the engagement of several stakeholders: the enterprise, its customers, partners and also competitor companies. The participation of all these parties enables the creation of network of information sharing and social knowledge [9].

\section{SMEs and Web 2.0}

As Levy and Powell [6] argue , SMEs' strategies tend to be emergent, informal, and based on reactive decisions. Their strategies are, above all, focused on surviving. On the other hand, these companies are characterized by a high level of flexibility and innovation that can mitigate the weaknesses that have been highlighted. The fact that Web 2.0 tools are mainly free of charge and easy to use, makes them an important ally for SMEs. The technical accessibility of Web 2.0 and employees' familiarity with tools in their private lives are some of the forces driving E2.0's deployment [7].

\subsection{The Benefits of Using Web 2.0 in SMEs}

Gagliardi [9] conducted a study on SMEs from France, Italy, Poland and Spain from several activity sectors that amounted to 85 questionnaires in total. The author reports 
that the adoption of Web 2.0 technologies inside SMEs remains timid and as a complement to other innovative tools. "SMEs see this technology with particular interest concerning the potential offered but they are also concerned about making the firm's boundaries more porous." [9].

SMEs face challenges at several levels, namely in terms of knowledge management, reduced degree of knowledge transfer, insufficient information on communication and cooperation practices. Additionally, SMEs still employ more traditional methods of information sharing and communication. Hence, it is important to invest in new methods of corporate learning to guarantee that SMEs are empowered to address these issues. [10]. One of the resources derived from E-Learning 2.0, are communities of practice. Communities of practice have the potential to support innovation and enable the development of new skills inside SMEs. These communities are ideal instruments for corporate learning because they overcome space and time obstacles, two of the biggest impediments for training professionals [10]. Web 2.0 is also suggested as a valuable solution for the isolation of SMEs, which are mainly faced with the need to solve their issues alone, namely in terms of training. Social networks and communities of practice have been often indicated as a viable answer [11].

Collaborative technology enhances intra and inter-enterprises' communication practices [12]. Software can pose a challenge to SMEs budget and IT capacity of response. The notion of software as service benefits smaller companies which lack the capital and human resources to employ expensive and intricate softwares that were mainly designed for enterprises of significant size [7]. Social networks have proved their preponderance over traditional marketing in terms of word-of-mouth generation. Also social network sites have been demonstrating their value in creating revenue and platforms for online shopping [13]. Social network sites play an important role in the direct connection between customers and businesses, they enable the creation of communities and they are a important asset in information distribution and feedback collection [13]. The use of online social networks for business purposes obeys to a set of rules of its own that adapts the social nature of these sites with the intention of promoting sales and attract clients. Overall, it is important to encourage participation, to listen to what is being said about specific products and brands, to address negative feedback, to ensure a presence in mainstream websites and to use a professional, but informal tone [14].

\subsection{Web 2.0 Challenges for SMEs}

There is a general tendency for SMEs to be significantly less prone to deploy pioneering technology than larger enterprises [15].

The consideration of Web 2.0 technology as a valuable business asset requires SMEs to be aware of the challenges that this union poses. The absence of control over the content that is created, edited and shared in Web 2.0 platforms constitutes one of the most significant issues in the full adoption of E2.0. SMEs are often concerned with matters related to Intellectual Property Rights that emerge from the use of Web 2.0 instruments. Alongside with these issues of control, the ubiquitous character of Social Web's technology is often indicated as a heavy hurdle [4]. SMEs' reduced 
human capital is sometimes seen as an impediment for the proliferation of E2.0, in the sense that it restrains internal networking [4]. Moreover the allocation of personnel for the management of social technology is challenging. The fact that the ratio of digital natives in management teams remains low is a deterrent for E2.0's growth [4].

The absence of relevant methods of assessment of Web 2.0's effectiveness constitutes an important downside of its deployment in business settings. It is important to underline that in terms of marketing efficacy, for example, the conventional evaluation methodologies of success are inadequate to measure E2.0's outcomes [13].

The benefits of E2.0 are not felt uniformly through the different economical sectors. Certain businesses, such as construction or house maintenance services, have a more limited use for Web 2.0 technology than SMEs that specialize in IT consultancy or Web design, for example [7].

\section{Methods}

The empirical evidence of Web 2.0 implementation inside SMEs is paramount both for researchers and practitioners. Hence to add to the current body of research on this subject, this study isolated a specific group of Portuguese SMES and questioned their employees as to the dissemination of Web 2.0 practices inside their enterprises. This group was composed of a sample of 438 companies which were selected from a total population of 1481 "excellence" companies. The "SME excellence" is an annual award which prizes the best SMEs in Portugal. The sample was obtained via a simple stratified sampling method to guarantee the representativeness of the selected SMEs. The participants were asked to respond to an online questionnaire focused on collecting demographic data, information on each company's specific features and records on the corporate and personal usage of Web 2.0.

\section{$5 \quad$ Results}

The data, from the online questionnaire that was administered to 438 SMEs in Portugal, purported that technologies such as blogs, wikis, RSS and podcasts have reasonable levels of initial adoption.

The survey was completed by 99 participants aged 31 to 54 years old. Around $70 \%$ of the respondents were male. In terms of their role inside their companies, about one third of all participants were CEOs and around $20 \%$ were part of management. The participants reported that privately, their use of Web 2.0 remains overshadowed by their use of email. Additionally, wikis and podcasts are in their initial stages of adoption, while blogs and instant messaging are assuming a growing part in the private sphere of the respondents lives. The preponderance of conventional communication methods was equally evident, when the respondents were questioned about corporate communication: e-mail (circa 67\%), telephone/mobile phone (circa 47\%) and personal contact (circa 50\%). This result is supported by De Saulles [7] conclusion that SMEs remain greatly dependent on electronic mail as their basic communication instrument. 
With regard to the concept of E2.0 there was a significant division among the participants, which became apparent in the different levels of knowledge about and implementation of E2.0 (Figure 1).

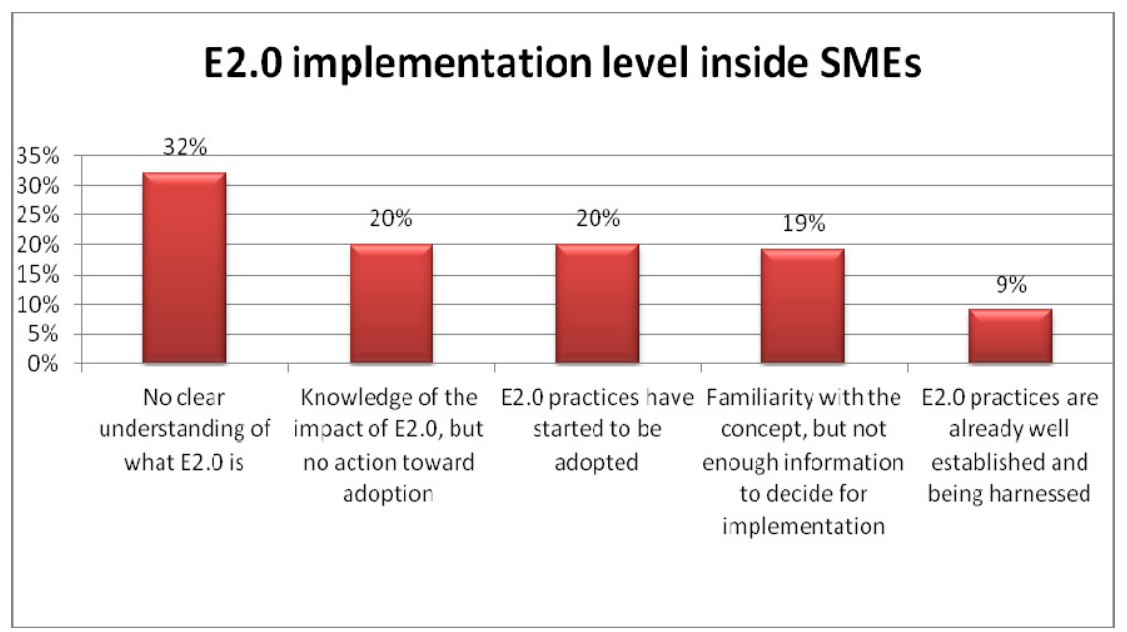

Fig. 1. Different levels of E2.0 adoption inside SMEs

A relevant number $(32 \%)$ of SMEs' employees remains confused as to the definition of E2.0, what it entails exactly and the extent of its business value. Moreover, around $19 \%$ of the participants stated that despite having an elementary notion of what E2.0 amounts to, that knowledge is still insufficient cause for deciding to use it. Among those who declared that they were familiar with the term, there was still a significant part of them $(20 \%)$ that does not use it in practice. Those on an initial phase of adoption account for $20 \%$ of the total respondents. The pioneers of E2.0 implementation constitute $9 \%$ of the sample and state that E2.0 is well rooted inside their SMEs and its potential is being maximised.

Furthermore, around $29 \%$ of survey participants confirmed that E2.0 implementation in their companies is integrated in their business strategy and takes advantage of the efforts of employees and top management. E2.0 shows a high level of dissemination in organizations' departments. Also, 29\% of respondents said their company had spread E2.0 practices while $79 \%$ of survey participants confirmed that their organizations have recently been focusing on these technologies. More than $92 \%$ were sure that the impact was positive. Finally, the data showed that $83 \%$ of study participants were satisfied or very satisfied with E2.0. This percentage rises to $100 \%$ in companies that have established E2.0 practices.

\section{Guidelines for SME 2.0 Effectiveness}

As stated in the AT\&T and Consulting [16] study, there is no "Holy Grail" of E2.0 implementation, but there are certain measures that can be put in place to potentiate 
the successful implementation of E2.0 in SMEs. These technologies present advantages in terms of costs as they are mainly free or demand a low cost [7]. There is an outsourcing of innovation among customers, which may increase revenues and decrease cost. Additionally, there is sufficient motivation and a correct combination of incentives and organizational values involving all employees' voluntary use [17].

Culturally, SMEs must engage with flexible organizational structures and an open and innovative corporate culture [16]. In order to harness competitive advantage, these technologies should be integrated in the company's business strategy [18].

Every instrument that is used for marketing purposes needs to provide a clear and unequivocal account of its results. It is paramount to have the capacity to measure the effectiveness of Web 2.0 tools, namely in a context of fierce competitiveness, need for accountability and budgetary constraints. Given Web 2.0's interactive nature, the conventional marketing measures do not apply. One of the core elements of developing a thriving concept of SME 2.0 is the creation of suitable measurements [13]. Management represents a decisive role in the implementation of Information Technology (IT). The managers' impact is dictated by their mindset and their competences. Since managers play such a vital part in the adoption of innovative technology [15] it becomes imperative to engage them with Web 2.0, so that they can lead their companies towards SME 2.0.

Employees must also be considered in this Web 2.0 adoption equation. Their routine problem-solving skills can benefit significantly from the information flow and sharing that Web 2.0 allows, improving their ability to address day to day issues [3]. The "generational turnover of entrepreneurs" [4] is expected to favor Web 2.0 technologies which will impact the future of E2.0. The generation commonly known as digital natives is likely to invest in the development of interactive and collaborative technologies [4]. SMEs' reduced human capital is sometimes seen as an impediment for the proliferation of E2.0, in the sense that it restrains internal networking. Moreover the allocation of personnel for the management of social technology is challenging [4]. Web 2.0 is people-centered, its improvement is dependent on the activity and engagement of its users. Similarly, SME 2.0 requires the employees of SMEs to actively interact with the Web 2.0 applications that their companies have chosen to implement [19].

User participation is a underlying driver of Web 2.0 presence, according to the Web 2.0 reference framework proposed by Isaias, Miranda and Pifano [20], which consists of the following critical success factors: Users' inputs; Users' critical mass figures; Ease of use of component; Component feedback; Availability of content to justify users' access; User content addition features; User content development tools; and Revenue models. Since participation is greatly dependent on trust, SMEs should make an effort to develop acceptable levels of trust among their partners. A strategy that can be followed to create such trust is the exchange of information, the sharing of mutually beneficial knowledge [19].

Stocker and Tochtermann [21] concluded in their study on the use of blogs among SMEs, that the employees were less inclined to read their enterprise blog, if its content was perceived as being significantly less important than their day to day work responsibilities. This raises an important issue in terms of real value for individual 
productivity. It is paramount to ensure that whatever Web 2.0 tools might be used, their benefits must be clear to the employees.

Albeit the nearly ubiquitous use of the internet in SMEs, there are certain Webbased resources that remain untapped by enterprises of reduced size due to budget limitations and lack of skills. The technological innovation of SMEs must be derived from an in-depth knowledge of their needs, so that collaborative platforms can be created to assist organizational success [12]. Moreover, in order to fruitfully deploy Web 2.0 technologies, SMEs must undergo a transformation process that relies greatly on a mental model shift. Web 2.0 requires openness to the exterior to potentiate innovation. Hence SMEs must learn to look outside their own wall and people to search for more relevant resources [19].

\section{Conclusion}

Fierce competition, budgetary constrictions and demand for IT innovation are conducing SMEs toward a path of Web 2.0 adoption. Similarly to what has been happening to larger companies and renowned brands, SMEs seem to be progressing in the direction of E2.0 precepts.

The affordances of E2.0 have reshaped internal and external working relationships and practices. The benefits of E2.0 are manifested mainly in a closer relationship with customers, a more personalized product delivery, viral marketing and the collaborative working routines. "Enterprise 2.0 is much more about businesses' adoption of "2.0 mindsets" than with the consumer-facing side of the coin." [8]. As Web 2.0 technologies become increasingly popular in the business sector it is paramount to examine how SMEs are dealing with the changes it warrants and the benefits it allows.

The assessment of Portuguese SMEs' fluency in E2.0 depicts an initial concern with innovation and intent to employ Web 2.0 tools and projects the need for a broader diagnose of Web 2.0's level of incursion into small and medium businesses.

Acknowledgements. Authors wish to thank ADVANCE research center and ISEG Lisboa School of Economics and Management - University of Lisbon.

\section{References}

1. McAfee, A.P.: Enterprise 2.0: The dawn of emergent collaboration. Management of Technology and Innovation 47(3) (2006)

2. Hinchcliffe, D.: Why all the fuss about Web 2.0. Infonomics 24(1), 26-31 (2010)

3. Peris, M., et al.: Acceptance of Professional Web 2.0 Platforms in Regional SME Networks: An Evaluation Based on the Unified Theory of Acceptance and Use of Technology. In: 2013 46th Hawaii International Conference on System Sciences (HICSS). IEEE (2013)

4. Gagliardi, D.: Next generation entrepreneur: innovation strategy through Web 2.0 technologies in SMEs. Technology Analysis \& Strategic Management 25(8), 891-904 (2013) 
5. Blinn, N., Lindermann, N., Fäcks, K., Nüttgens, M.: Web 2.0 in SME networks - A design science approach considering multi-perspective requirements. In: Nelson, M.L., Shaw, M.J., Strader, T.J. (eds.) AMCIS 2009. LNBIP, vol. 36, pp. 271-283. Springer, Heidelberg (2009)

6. Levy, M., Powell, P.: Strategies for Growth in SMEs: The Role of Information and Information Sytems. Butterworth-Heinemann (2004)

7. De Saulles, M.: Never too small to join the party. Information World Review, 10-12 (2008)

8. Frappaolo, C., Keldsen, D.: Enterprise 2.0: Agile, Emergent \& Integrated. AIIM Intelligence Quarterly, AIIM: Silver Spring, MD (2008)

9. Gagliardi, D.: Next Generation Entrepreneur: How Web 2.0 Technologies Creep into SMEs (2011)

10. Hamburg, I., Engert, S., Anke, P.: Communities of Practice and Web 2.0 to support learning in SMEs, Online PDF (2007)

11. Hamburg, I., Hall, T.: Social Networks, Web and Mentoring Approaches in SME Continuing Vocational Education and Training. Journal of Information Technology and Application in Education 2(2) (2013)

12. Robertson, A., et al.: The search for innovators and early adopters of e-collaborative technologies within small and medium sized enterprises in the UK (2007)

13. Michaelidou, N., Siamagka, N.T., Christodoulides, G.: Usage, barriers and measurement of social media marketing: An exploratory investigation of small and medium B2B brands. Industrial Marketing Management 40(7), 1153-1159 (2011)

14. Isaías, P., Pífano, S., Miranda, P.: Social Network Sites: Modeling the New BusinessCustomer Relationship. In: Social Networking and Community Behavior Modeling: Qualitative and Quantitative Measures, pp. 248-265. IGI Global (2012)

15. Wamba, S.F., Carter, L.: Twitter adoption and use by SMEs: An empirical study. In: 2013 46th Hawaii International Conference on System Sciences (HICSS). IEEE (2013)

16. AT\&T and E.S. Consulting Speeding the Adoption of Enterprise 2.0. (2009)

17. Manyika, J.M., Roberts, R.P., Sprague, K.L.: Eight business technology trends to watch. McKinsey Quarterly 1, 60 (2008)

18. Levy, M., Powell, P., Yetton, P.: SMEs: aligning IS and the strategic context. Journal of Information Technology 16(3), 133-144 (2001)

19. Lindermann, N., Valcárcel, S., Schaarschmidt, M., von Kortzfleisch, H.: SME 2.0: Roadmap towards Web 2.0-Based Open Innovation in SME-Networks - A Case Study Based Research Framework. In: Dhillon, G., Stahl, B.C., Baskerville, R. (eds.) CreativeSME 2009. IFIPAICT, vol. 301, pp. 28-41. Springer, Heidelberg (2009)

20. Isaías, P., Miranda, P., Pífano, S.: Critical success factors for web 2.0 - A reference framework. In: Ozok, A.A., Zaphiris, P. (eds.) OCSC 2009. LNCS, vol. 5621, pp. 354-363. Springer, Heidelberg (2009)

21. Stocker, A., Tochtermann, K.: Investigating Weblogs in Small and Medium Enterprises: An Exploratory Case Study. In: BIS, Workshops (2008) 